\title{
Características atuais associadas à história de aborto provocado
}

\section{Current characteristics associated with the history of induced abortion}

\author{
Ellen Hardy", Rosely G. Costa"**, Telma Rodrigues"**, Teresinha M. de Moraes
}

\begin{abstract}
HARDY, E. et al. Caracteristicas atuais associadas à história de aborto provocado. Rev. Saúde Pública, 28: 82-5, 1994. Com o objetivo de analisar a associação de algumas caracteristicas sociodemográficas atuais com o fato de ter realizado ou não um aborto, foram estudadas 138 alunas de uma universidade brasileira, que haviam tido pelo menos uma gravidez. Essas alunas foram identificadas dentre as 937 que devolveram, pelo correio, questionário auto-respondido, anonimamente, distribuído a todas as alunas da graduação. As alunas foram divididas em dois grupos, segundo tenham feito pelo menos um aborto ou não. Constatou-se que a maior proporção de mulheres que havia abortado esteve entre aquelas com até 24 anos de idade, sem companheiro, sem religiaao e sem nenhum filho vivo por ocasião do estudo. A análise por regressão logística apontou não ter filhos vivos como característica atual associada à realização de um aborto.
\end{abstract}

Descritores: Aborto induzido, estatística. Fatores socioeconômicos.

\section{Introdução}

O aborto provocado é um assunto debatido mundialmente, sobretudo nos países onde ele é considerado crime, como é o caso do Brasil. Discutem-se as razōes que levam as mulheres a abortar e as conseqüências dessa decisão, tratando o abortamento como uma questão de saúde da mulher e do bem estar da familia $\left(\mathrm{Cook}^{2}, 1991\right)$.

De um modo geral, toda a responsabilidade quanto à decisão de levar adiante uma gravidez ou não tem sido tradicionalmente atribuída à mulher.

* Trabalho realizado no Centro de Pesquisas e Controle das Doenças Materno-Infantis (CEMICAMP), parcialmente financiado pela Universidade Estadual de Campinas (UNICAMP), Programa Latinoamericano de Capacitación e Investigación en Reproducción Humana (PLACIRH), International Women's Health Coalition (IWHC) e Population Council.

** Departamento de Tocoginecologia da Faculdade de Ciências Médicas da Universidade Estadual de Campinas (UNICAMP) e Centro das Doenças Materno-Infantis (CEMICAMP) - Campinas, SP - Brasil

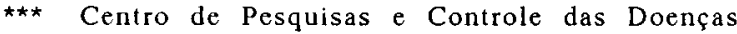
Materno-Infantis (CEMICAMP) - Campinas, SP - Brasil

Separatas/Reprints: E. Hardy - Caixa Postal 6181 - 13081-970 Campinas, SP - Brasil

Edição subvencionada pela FAPESP. Processo 94/0500-0
Embora quase todos os países, com algumas exceções, é claro, manifestem atualmente a tendência de estabelecer a igualdade constitucional e legal entre homens e mulheres, com respeito à gravidez, sobrecarregam-se estas últimas e praticamente não se fala da participação masculina. Assim, quando uma mulher faz um aborto ela tende a ser considerada a única responsável por ele e, se a legislação do seu país o considera crime, ela é criminosa principal (Cook ${ }^{2}, 1991$ ).

A decisão de ser ou não mãe é freqüentemente vista apenas como de ordem individual, da mulher, omitindo-se o envolvimento de série de fatores econômicos e sociais, além de implicar as condições da relação dela com o companheiro (Verardo ${ }^{5}$, 1987). Na verdade, é uma questão complexa discutir porque algumas mulheres chegam a abortar e outras não. Trata-se de uma decisão que envolve elementos de cunho pessoal, econômico e social ao mesmo tempo. Se é difícil discutir o assunto, é claro que mais difícil ainda é a posição de quem se sente compelida a tomar essa decisão. Obviamente, nem todas as mulheres que chegam a pensar em abortar realmente o fazem. Por exemplo, uma pesquisa feita com alunas e funcionárias de uma universidade brasileira mostrou que entre 369 funcionárias que pensaram em abortar, $72 \%$ de fato o fizeram. As características dessas mulheres, por ocasião do estudo, associadas a ter feito o aborto, foram o número 
de filhos vivos, o de gravidezes, escolaridade e idade (Hardy e col ${ }^{4}, 1991$ ).

O objetivo do presente trabalho foi verificar se existiam características sociodemográficas do grupo de alunas estudadas, associadas à história pregressa de aborto provocado.

\section{Material e Método}

Em 1990, conforme relatado em trabalho anterior (Hardy $\left.{ }^{4}, 1991\right)$, foi desenvolvida pesquisa em uma universidade brasileira, em população constituída de todas as funcionárias e alunas de graduação. Os dados foram obtidos através de um questionário auto-respondido, pré-testado, no qual não foi pedida nenhuma informação que permitisse identificar quem respondeu. Junto com o questionário foram distribuidos: uma carta explicando a pesquisa e um envelope carta-resposta comercial para a devolução do questionário. A entrega do material às alunas aconteceu no ato da matrícula para o segundo semestre de 1990.

Foram recebidos 937 questionários respondidos pelas alunas, que corresponderam a $42 \%$ do total pesquisado. No presente trabalho foram analisadas as respostas de 138 alunas que tinham tido pelo menos uma gravidez, sendo que 82 delas realizaram pelo menos um aborto. Foi considerado, para o estudo, o último aborto provocado.

Os questionários recebidos foram revisados, checando-se a consistência das respostas. Estas foram digitadas duas vezes, por pessoas diferentes, utilizando-se para isto o módulo de entrada de dados SPSS PC-DE. Corrigiram-se as inconsistências e os erros lógicos. Os dados foram analisados com o Statistical Package for Social Science - PC (SPSS-PC) e o Statistical Analysis System (SAS). Utilizou-se o teste de qui-quadrado para tabelas de contingência (Armitage ${ }^{1}$, 1987), e regressão logística $\left(\mathrm{Cox}^{3}, 1970\right)$.

No modelo utilizado para a regressão foram incluídas as seguintes variáveis: variáveis dependente: aborto provocado ( $\mathrm{sim} /$ não); variáveis independentes: idade (anos), estado marital (sem companheiro/com companheiro), religião (com/sem); número de gravidezes (uma/duas ou mais); número de filhos vivos (nenhum/um ou mais). Só foram analisadas as mulheres que forneceram informações para todas essas variáveis.

\section{Resultados}

Algumas características das alunas estudadas estão apresentadas na Tabela 1. Mais da metade tinha de 18 à 24 anos de idade, tinha tido uma gravidez e nenhum filho vivo por ocasião do estudo. Quase a metade delas era solteira e de religião católica.

Houve diferenças estatisticamente significativas entre os dois grupos nas seguintes variáveis: idade, estado marital, religião e número de filhos vivos. Abortaram com maior freqüência as alunas

Tabela 1. Caracteristicas selecionadas da população estudada.

\begin{tabular}{lc}
\hline $\begin{array}{c}\text { Caracteristicas } \\
\text { Idade* } \\
18-24\end{array}$ & $\%$ \\
$25-29$ & 56,2 \\
30 ou + & 26,2 \\
Estado marital & 17,3 \\
Solteira & \\
Casada & 47,1 \\
Amasiada/vive junto & 36,2 \\
Separada/divorciada & 8,7 \\
Religiăo & 8,0 \\
Católica & \\
Outras & 48,6 \\
Nenhuma & 18,0 \\
Número de gravidezes & 33,3 \\
1 & \\
2 & 64,5 \\
3 ou + & 18,8 \\
Número de filhos vivos & 16,6 \\
Nerhum & \\
1 & 55,8 \\
2 & 26,8 \\
3 & 13,0 \\
\hline Total de Mulheres & 4,3 \\
\hline
\end{tabular}

* Faltou informação de uma mulher. 
mais jovens, as sem companheiro, sem religião e sem nenhum filho vivo por ocasião do estudo, comparadas às que não abortaram (Tabela 2).

$\mathrm{Na}$ análise por regressão logística, estudando todas as mulheres e incluindo todas as variáveis apresentadas na Tabela 2, observou-se que o único fator significativamente associado a ter realizado pelo menos um aborto, foi o número de filhos (Tabela 3).

Tabela 2. Alunas que fizeram ou não um aborto, segundo caracteristicas atuais.

\begin{tabular}{lccc}
\hline \multirow{2}{*}{ Caracteristicas } & \multicolumn{2}{c}{ Abortaram } & Total \\
& Sim & Näo & \\
\hline $\begin{array}{l}\text { ldade*\& } \\
\quad \text { Até } 24 \text { anos }\end{array}$ & 73 & 27 & 77 \\
$\quad 25$ anos ou + & 43 & 57 & 60 \\
Estado marita/** & & & \\
$\quad$ Sem companheiro & 82 & 18 & 76 \\
$\quad$ Com companheiro & 32 & 68 & 62 \\
Religião** & & & \\
$\quad$ Com & 50 & 50 & 92 \\
$\quad$ Sem & 78 & 22 & 46 \\
$N^{2}$ de gravidezes & & & \\
$\quad$ Um & 63 & 37 & 89 \\
$\quad$ Dois ou mais & 53 & 47 & 49 \\
$N^{8}$ de filhos vivos & & & \\
$\quad$ Nenhum & 91 & 9 & 77 \\
Um ou mais & 20 & 80 & 61 \\
\hline
\end{tabular}

\& Faltou informação de uma mulher.

* $p<0,001$; ** $p<0,0001$; *** $p<0,01$

Tabela 3. Fator significativamente associado a ter feito um aborto, na regressão logística. Todas as mulheres*

\begin{tabular}{llll}
\hline Variável & Coefic. & $\begin{array}{c}\text { Erro } \\
\text { padrão }\end{array}$ \\
\hline
\end{tabular}

\begin{tabular}{llll}
$\begin{array}{l}\text { Filhos vivos }(0=1 / 1 \\
\text { ou mais }=0)\end{array}$ & 3,6889 & 0,5112 & $<0,0001$ \\
Constante & $-1,3863$ & 0,3227 & $<0,0001$ \\
\hline
\end{tabular}

* Faltou informação da idade de uma mulher.

\section{Discussão}

O estudo encontrou uma característica atual (número de filhos vivos) associada com ter feito pelo menos um aborto. Entretanto, a metodologia utilizada na pesquisa tem a limitação da representatividade. Como o questionário era auto-respondido, não foi possível saber se o grupo que respondeu era igual ou não ao que não o fez. Apesar disso, como os dados foram coletados de forma anônima, provavelmente permitiu que as mulheres se sentissem mais à vontade para responder com sinceridade às questões, propiciando respostas confiáveis. Não há nenhuma intenção de generalizar os resultados para fora desse grupo, e também não foi encontrado nenhum estudo semelhante para que se pudesse fazer comparação.

O fato de significativamente mais mulheres com até 24 anos de idade terem praticado o aborto sugere a dificuldade em assumir uma gravidez por parte das universitárias mais jovens, talvez por dependerem ainda dos pais e não estarem planejando ter um filho.

A maior percentagem de aborto entre mulheres sem companheiros poderia ser o resultado da necessidade social de ocultar uma gravidez, indicando o preconceito em relação à maternidade fora do casamento e as pressões sociais sofridas pelas mulheres nesse sentido. Outra explicação seria a dificuldade de assumir e sustentar um filho sozinha.

A constatação de que as alunas que mais abortaram foram as que se declararam sem religião parece indicar que a religião pode ter agido como um freio no que se refere à realização do aborto. Finalmente, a associação entre realização do aborto e nenhum filho vivo pode estar indicando que as estudantes controlaram sua fecundidade através do aborto provocado. E o fato de realizar o aborto que explica não ter filhos e não o inverso.

\section{Agradecimentos}

À Carlos Mora Rodriguez e Sergio Vera Schneider pela colaboração no processo de computação e análise dos dados.

HARDY, E. et al. [ Current characteristics associated with the history of induced abortion]. Rev. Saúde Pública, 28: 82-5, 1994. For the purpose of analysing the association between selected current socio-demographic characteristics 
and the history of induced abortion, 138 students of a Brazilian university, who had been pregnant at least once, were studied. These students were identified from among the 937 who returned, by mail, a self-administered, anonimous questionnaire distributed to all the femele undergraduates. The subjects were divided into two groups, those who had and those who did not have a history of induced abortion. It was found that the largest percentage of women who had already had an induced abortion were of less than 24 years of age, were not living in marital union, had no religious affiliation and no living children at the time of the study. Analysis by logistic regression showed that having no living children was the only current characteristic associated with having had an induced abortion.

Keywords: Abortion induced, statistics. Socioeconomic factors.

\section{Referências Bibliográficas}

1. ARMITAGE, P. \& BERRY, G. Statiscal methods in medical research. Oxford, Blackwell Scientific Publication, 1987.

2. COOK, R.J. Leis e políticas sobre o aborto: desafias e oportunidades. São Paulo, IWHC, 1991.

3. COX, R.K. The analysis of binary data. London, Methnenx Co. Ltd., 1970.

4. HARDY, E. et al. Aborto provocado: diferença entre o pensamento c ação. Rev. Ginec. Obstet., 2: 111-6, 1991.

5. VERARDO, M.T. Aborto: um direito ou um crime? São Paulo, Modema, 1987.

Recebido para publicação em 26.8.1992

Reapresentado em 8.10.1993

Aprovado para publicação em 11.1.1994 